\title{
RELATING MAGNETIC PROPERTIES OF MUNICIPAL SOLID WASTE CONSTITUENTS TO IRON CONTENT - IMPLICATIONS FOR ENHANCED LANDFILL MINING
}

\author{
Daniel Vollprecht ${ }^{1, \star}$, Christin Bobe ${ }^{2}$, Roman Stiegler ${ }^{1}$, Ellen Van De Vijver ${ }^{2}$, Tanja \\ Wolfsberger ${ }^{1}$, Bastian Küppers ${ }^{1}$ and Robert Scholger ${ }^{3}$ \\ ${ }^{1}$ Montanuniversität Leoben, Chair of Waste Processing Technology and Waste Management, Franz-Josef-Str. 18, 8700 Leoben, Austria
${ }^{2}$ Ghent University, Department of Environment, Coupure Links 653, 9000 Ghent, Belgium \\ ${ }^{3}$ Montanuniversität Leoben, Chair of Applied Geophysics, Peter-Tunner-Str. 25, 8700 Leoben, Austria
}

Article Info:
Received:
7 June 2019
Revised:
9 September 2019
Accepted:
11 September 2019
Available online:
23 December 2019
Keywords:
Landfill mining
Geophysical exploration
Magnetics
Magnetic susceptibility
Metals
Waste

\section{INTRODUCTION}

Landfill mining (LFM) (Krook, Svensson, \& Eklund, 2012) and more recently Enhanced Landfill mining (ELFM) (Jones, et al., 2013), the recovery of resources from landfills, have gained increasing attention in the last few decades. The main focus of mining municipal solid waste (MSW) landfills is calorific fractions (20-30 wt.\% dry matter) for energy recovery and metals (1-5 wt-\% dry matter) for direct material recovery (Krook, Svensson, \& Eklund, 2012). Whereas, decomposed organic and weathered mineral materials, often summarized under the term fine fractions (50-60 wt.-\%) (Hernández Parrodi, Höllen, \& Pomberger, 2018), and inert material (10 wt.-\%) are mostly not recyclable (Wolfsberger, et al., 2015). MSW metal content can vary significantly within, and for different, landfills (Krook, Svensson, \& Eklund, 2012), as it depends mainly on the fresh waste composi- tion (Burnley, 2007) and mechanical-biological pre-treatment (Leikam \& Stegmann, 1999). From an economic point of view, a relatively high proportion of metals in a landfill is the decisive parameter for a positive assessment of an ELFM project (Winterstetter, Laner, Rechberger, \& Fellner, 2015). Therefore, it is relevant to investigate the metal content of a landfill prior to deciding the potential for ELFM.

Often, invasive methods are applied to estimate the material composition of landfills, this mainly includes drilling, and trenching, followed by manual sorting of the sampled material (Mor, Ravindra, de Visscher, Dahiya, \& Chandra, 2006). However, invasive techniques are expensive and time-consuming. Due to these disadvantages, often only small volumes of a landfill are explored (McCann, 1994). This is problematic due to the strong heterogeneity of MSW, which can cause the results to be unreliable and/or poorly representative. 
Using non-invasive geophysical methods, larger sections of landfilled waste can be investigated in terms of their in-situ physical properties, and they can be scanned quickly, and hence, at relatively low expense. Such methods have been applied for decades in exploration of geogenic deposits like ores or petroleum (Dobrin \& Savit, 1960), and have also proven to be useful for the investigation of landfills. However, most geophysical studies of landfills focus on environmental problems arising from the landfilled waste, and material composition is often not explored (Orlando \& Marchesi, 2001) (Hermozilha, Grangeia, \& Senos Matias, 2010) (Porsani, et al., 2004). However, recently attempts towards landfill characterisation in the context of ELFM projects have included the determination of leachate saturation levels and thickness of the waste by vertical electric sounding, electrical resistivity tomography, induced polarization and seismic diffraction techniques (Cardarelli \& di Filippo, 2004). Additionally, since the development of the concept of ELFM, a few studies have focused on geophysical exploration through electromagnetic induction in view of supporting the decision of, and relevance of, an ELFM scenario (e.g., (Bobe, Van De Vijver, \& Van Meirvenne, 2018); (Van De Vijver \& Van Meirvenne, 2016)).

Magnetic methods are mainly applied to identify individual objects (e.g. drums) in landfills (Prezzi, Orgeira, Ostera, \& Vasquez, 2005). On the contrary, in ELFM the average material composition of an entire landfill, or at least a compartment, is crucial (Krook, Svensson, \& Eklund, 2012), not individual objects. For example, in one simpler nonMSW ELFM case study, landfilled foundry sands were distinguished from iron-rich materials in an industrial landfill by the absence of magnetic anomalies (Zanetti \& Godio, 2006). In general, iron scrap in MSW landfills does not form whole compartments or layers, but occurs as individual objects of various sizes $(\mu \mathrm{m}-\mathrm{m})$ which are mixed with other MSW constituents like plastics, wood, inert materials and decomposed organics. For this reason, for ELFM of MSW landfills, the approach to identify individual objects is not valuable, but rather average MS values of whole landfills or larger parts of a landfill are required. In the recent ELFM study of Yannah, Martens, van Camp, \& Walraevens (2019), metal enrichments were differentiated qualitatively to plastic enrichments. However, in general, quantitative interpretation of geophysical measurements in terms of waste composition remains challenging.

Iron is the most common metal in landfills (García López, et al., in press), and the magnetic susceptibility (MS), which is the degree of magnetization of a material in response to an applied magnetic field, of iron is large compared to other materials (Schenck, 1996). Thus, geophysical prospecting with magnetic methods is a logical method to apply in ELFM evaluation. Magnetic surveying allows one to derive subsurface MS values, and as the MS of the bulk of landfill materials is negligible compared to the contribution from iron, it might be possible to estimate iron content from magnetic data.

In magnetic exploration, there are two different approaches.

In gradiometer magnetic measurements, the strength of the Earth's magnetic field with respect to an accurate location and time is measured. By comparing the geomagnetic reference field with temporal changes of the field during the survey time, a local magnetic anomaly is derived. Such anomalies can be linked to magnetisable objects in the subsurface. The magnetic susceptibility of a material gives a measure of its degree of magnetizability. In general, the interpretation of magnetic anomalies is not straightforward due to various complications arising from the strongly variable nature of waste materials and dynamic landfill conditions. Relating to the former, objects with two types of magnetization may occur: (i) induced magnetization due to the present Earth's magnetic field, and (ii) remanent magnetization due to an earlier exposure to a magnetic field, which might have had a different orientation than the currently prevailing Earth magnetic field. The interaction of these magnetization effects, for the entire collection of individual magnetic objects present in landfilled waste, impedes unique interpretation of magnetic data in terms of waste properties. For MSW landfills, it is assumed that the remanent magnetization is even harder to capture than for rocks, as landfills usually consist of many small objects whose remanent magnetization is randomly distributed and therefore, levels off at a larger scale, not locally, such that magnetic data interpretation of landfills is more complicated than interpretation of geological magnetic anomalies.

To derive surface MS, active induction measurements are commonly applied. In these measurements an artificial alternating electromagnetic field is applied to the surface. The response of the illuminated volume to the alternating field is then recorded and can be linked to its magnetic susceptibility.

MS values of inorganic materials like copper $(\mathrm{Cu},-9.63$ $\left.\times 10^{6}\right)$, iron $\left(\mathrm{Fe}, 2.00 \times 10^{5} \mathrm{SI}\right)$, water $\left(\mathrm{H}_{2} \mathrm{O},-9.05 \times 10^{-6} \mathrm{SI}\right)$ and air $\left(3.60 \times 10^{-7} \mathrm{SI}\right)$ were summarized by Schenck (1996). With respect to the prediction of the content of iron and other ferrous metals, it has to be stressed that the MS values for different iron alloys can vary around eight orders of magnitude. Data for organic waste constituents like polyethylene ( $\mathrm{PE}, 4.34 \times 10^{-5} \mathrm{SI}$ ), polyethylene terephthalate (Selwood, Pardo, \& Pace, 1950) and for wood (-3.88 x $10^{-7} \mathrm{SI}$ ) (Phaovibul, Loboda-Cackovic, Hosemann, \& Balta-Calleja, 1973) are limited and for some organic polymers like cotton or polypropylene (PP) no data was found. All relevant and available literature values are summarized in Table 1. It can be seen that due to its ferromagnetism, iron content can be expected to dominate magnetic anomaly data. Thus, we expect to find a relationship between the absolute values of magnetic anomalies and the landfill iron content.

For ELFM projects the values for virgin substances are of restricted applicability as material groups which are derived from mechanical processing, still contain fine-grained contaminations of other materials and are degraded in landfills. For an economic assessment of ELFM, only the share of metals that is obtained by mechanical processing or manual sorting can be compared to magnetic data and is therefore relevant to consider. Degraded and contaminated waste fractions, which are obtained after mechanical processing of fresh or landfilled MSW, have undergone 
TABLE 1: Literature values for magnetic susceptibility of pure materials (1) = (Schenck, 1996), 2 = (Phaovibul, Loboda-Cackovic, Hosemann, \& Balta-Calleja, 1973), 3 = (Rakos, Murin, Kafka, Varga, \& Olcak, 1984), 4 = (Selwood, Pardo, \& Pace, 1950)

\begin{tabular}{|c|c|c|}
\hline Material & Formula/Abbreviation & Magnetic Susceptibility (SI) \\
\hline Pure iron (1) & $\mathrm{Fe}$ & $2.00 \cdot 10^{5}$ \\
\hline Magnetic stainless steel, martensitic (1) & $(\mathrm{Fe}, \mathrm{Cr})$ & $4.00 \cdot 10^{2}-1.10 \cdot 10^{3}$ \\
\hline Magnetite (1) & $\mathrm{Fe}_{3} \mathrm{O}_{4}$ & $7.00 \cdot 10^{1}$ \\
\hline Stainless steel, austenitic (1) & $(\mathrm{Fe}, \mathrm{Cr})$ & $3.52 \cdot 10^{-3}-6.70 \cdot 10^{-3}$ \\
\hline Goethite (1) & $\mathrm{FeOOH}$ & $1.46 \cdot 10^{-3}$ \\
\hline Polythylene (2) & PE & $4.34 \cdot 10^{-5}$ \\
\hline Air (1) & $78 \% \mathrm{~N}_{2}+21 \% \mathrm{O}_{2}$ & $3.60 \cdot 10^{-7}$ \\
\hline Quartz (1) & $\mathrm{SiO}_{2}$ & $-1.63 \cdot 10^{-5}$ \\
\hline Water (1) & $\mathrm{H}_{2} \mathrm{O}$ & $-9.05 \cdot 10^{-6}$ \\
\hline Copper (1) & $\mathrm{Cu}$ & $-9.63 \cdot 10^{-6}$ \\
\hline Polyethylene terephthalate (4) & PET & $-6.74 \cdot 10^{-7}$ \\
\hline Cellulose (3) & & $-3.37 \cdot 10^{-7}$ \\
\hline Fir wood (3) & & $-3.88 \cdot 10^{-7}$ \\
\hline
\end{tabular}

significant material changes, and might therefore, have a different magnetic susceptibility compared to that of virgin materials from industry. Therefore, a calibration of the magnetic model of a landfill (McCann, 1994) can only be validated when MS values of respective waste fractions are known. As such, the aim of magnetic exploration is to relate its results to the percentage of the ferrous metals fraction obtained by manual or mechanical sorting. Furthermore, for ELFM applications it has to be considered that ferrous metals may also occur as contaminations in other waste fractions.

In summary, two key issues hinder a quantitative iron content estimation in landfills using magnetic exploration methods: the change of the material during degradation in landfills and waste processing, and the large variation in intrinsic MS values of ferrous metals. These points motivate the two research questions addressed in this work: (i) to which degree do the MS values of virgin materials differ from those of waste fractions containing these materials, but which have been altered and have been contaminated by other materials, and (ii) can laboratory measurements of the MS of (mixtures of) individual waste fractions be related to total field magnetic measurements on site, and can the combination of laboratory and field measurements predict the iron content of a landfill?

To the best of our knowledge, quantitative studies for geophysical iron content exploration have not been presented yet. In order to predict the share of iron in landfills, the observed deviation of the total magnetic field intensity and the thereof derived bulk subsurface MS must be associated to the MS of different waste fractions.

To investigate our research questions, we approach the iron content estimation problem in three steps. First to answer research question (i) we conduct MS analyses on reference samples (i.e. waste fractions, and if not available, samples of materials which also occur in landfilled waste) and compare them to literature values of corresponding relevant materials. Second, we calculate the MS of waste mixtures based on compositions derived from manual sorting of samples obtained in a drilling campaign from an Austrian MSW landfill. The bulk MS calculation is based on MS values derived from the reference samples and the ratio of materials present. Third, we use the anomalous magnetic data from a survey at the respective Austrian MSW landfill to estimate the bulk MS of the waste along a profile by inverse modelling. The calculated mean MS for the drillcored material was compared to the inverse-modelled MS to answer research question (ii).

\section{MATERIALS AND METHODS}

\subsection{Magnetic Lab Tests}

In total, magnetic properties of twelve reference samples representing materials relevant in ELFM projects were investigated (Table 2). Six waste fractions were obtained from a landfill mining project (Muras, Küppers, Höllen, \& Rothschedl, 2018), five of them produced by manual sorting (polypropylene (PP), polyethylene (PE), paper \& paperboard, textiles and wood), and one from mechanical biological treatment (MBT), i.e. the light fraction of a windsifter. Shredded bottle lids (PE + PP + polyethyleneterephthalate, PET) and black plastics were obtained from a plastic recycling plant, two further samples, i.e. copper scrap and granulated pig iron (GPI, $d=5 \mathrm{~mm}$ ), were obtained from industrial partners, and building sand and potting soil were commercial products. In summary, 10 of 12 samples are waste samples characterized by contaminations of other materials, e.g. the iron fraction.

Sample bodies of all investigated reference samples were produced in non-compacted form in two open vessels of different size, a cube of $8 \mathrm{~cm}^{3}$ volume, and a cylinder $(\mathrm{h}=$ $9 \mathrm{~cm}, 10 \mathrm{~cm}, \mathrm{~V}=707 \mathrm{~cm}^{3}$ ). Overall, four different magnetic sensors were used to check data reliability. These were: the Exploranium KT-9 (sensitivity: $10^{-5} \mathrm{SI}$ units, measuring time $0.5 \mathrm{~s}$, frequency $10 \mathrm{kHz}$ ); the Bartington MS2 with MS2EI sensor (2 kHz); the Agico MFK1-FA Kappa bridge; and the KLF-3 Minikappa. The Explonarium and Bartington sensors were used for the larger test specimens and the Agico and the KLF-3 sensor for the smaller test specimens. Meas- 
TABLE 2: Reference samples for lab tests for the determination of magnetic properties.

\begin{tabular}{|c|c|c|c|}
\hline No. & Material & Sample Codes & Origin \\
\hline 1 & Polypropylene (PP) & PP-1 to PP-6 & Halbenrain Landfill \\
\hline 2 & Light fraction windsifter & LG-1 to LG-6 & Halbenrain Landfill \\
\hline 3 & Polyethylene (PE) & PE-1 to PE-6 & Halbenrain Landfill \\
\hline 4 & Shredded bottle lids & PET-1 to PET-6 & Recycling Plant \\
\hline 5 & Paper \& Paperboard & $\mathrm{K}-1$ to $\mathrm{K}-6$ & Halbenrain Landfill \\
\hline 6 & Textiles & TX-1 to TX-6 & Halbenrain Landfill \\
\hline 7 & Wood & $\mathrm{H}-1$ to $\mathrm{H}-6$ & Halbenrain Landfill \\
\hline 8 & Black plastics $(\mathrm{PE}+\mathrm{PP})$ & KS-1 to KS-6 & Recycling Plant \\
\hline 9 & Iron & FE-1 to FE-6 & Granulated pig iron (GPI), Steel Plant \\
\hline 10 & Copper & CU-1 bis CU-6 & Chair of Nonferrous Metallurgy, MUL \\
\hline 11 & Quartz sand, $0.3-1 \mathrm{~mm}$ & $\mathrm{~S}-1$ bis $\mathrm{S}-6$ & Quester BauProfi Quartz sand, lime-free, fire-dried \\
\hline 12 & Potting soil & $\mathrm{BE}-1$ to $\mathrm{BE}-6$ & Hornbach Universalblumenerde \\
\hline
\end{tabular}

urements with the Explonarium and Bartington sensor (12 measurements per material, per sensor and 24 measurements for light fraction (LG) samples), were conducted in direct contact with the material surface. The Bartington MS2 sensor was applied at different spots on the sample cube, whereas the Exploranium KT-9 sensor was applied at one single measurement spot due to its required larger sample size, which did not allow measuring different spots on one plane. Measurements with the Agico sensor were conducted in triplicate at two frequencies $(976 \mathrm{~Hz}, 3904$ $\mathrm{Hz}$ ). For measurements of the GPI sample, the cubes were only partly filled to $15 \pm 2 \%$ as MS values of completely filled cubes exceeded the calibration range.

The measured bulk MS values of partly filled cubes were converted to intrinsic MS values by considering the volume share of the investigated sample. To account for the MS of the sample cube, the average susceptibility of an empty sample cube was used as a blank and subtracted from the respective sample values.

The natural remanent magnetization (NRM; Mr) of the reference samples was investigated in free space and in the absence of any external magnetic field. The measurements were performed using two magnetometers, the Bartington Mag- $01 \mathrm{H}$ Fluxgate for $\mathrm{Cu}$ and $\mathrm{Fe}$, and the $2 \mathrm{G}$ Enterprises for all other samples. The samples were inserted in a cube with $8 \mathrm{~cm}$ edge length. For $\mathrm{Cu}$ and $\mathrm{Fe}$, the NRM was determined in three spatial directions and the average values were used to calculate the resulting magnetization vectors. The induced magnetization (Mi) of $\mathrm{Fe}$ and $\mathrm{Cu}$ was calculated according to equation 1 from the magnetic susceptibility determined by the AGICO sensor, as this sensor has the largest sensitivity. For $\mathrm{Cu}$ and $\mathrm{Fe}$, MS values for completely filled cubes were beyond the measuring range and therefore extrapolated from partly filled cubes.

$\mathrm{Mi}=0.7958 \mathrm{H} \bullet \chi$

$\mathrm{H}=$ magnetic field at the site; $\mathrm{x}=$ magnetic susceptibility, the factor 0.7958 is due to the conversion in $A / m$.

The contribution of $\mathrm{Mr}$ and $\mathrm{Mi}$ is expressed by the Königsberg factor $\mathrm{Q}=\mathrm{Mr} / \mathrm{Mi}$.

The viscous remanent magnetization (VRM) was deter- mined after subjecting the samples to the Earth's natural magnetic field for 30 days and a subsequent measurement of the magnetization using the Bartington Mag- $01 \mathrm{H}$ Fluxgate for $\mathrm{Cu}$ and $\mathrm{Fe}$, and the $2 \mathrm{G}$ Enterprises for all other samples. The change in direction of the vector of the magnetization was used to calculate the VRM using Remasoft 3.0 software.

\subsection{Magnetic Landfill Exploration}

An Austrian MSW landfill, landfill site 1 in (Wolfsberger, et al., 2015), was selected for geophysical exploration. The survey locations were recorded with an accuracy of $<1$ $\mathrm{m}$ using a Trimble Total-station TK GPS. The survey area is outlined in Figure 1. The magnetic total-field measurements were conducted following a grid setup with a spacing of $2 \mathrm{~m}$ in the east-west direction and $1 \mathrm{~m}$ in the northsouth direction, resulting in 4696 measurement points. Two GEM 19-OH proton-precession magnetometer sensors were placed at 1 and $2 \mathrm{~m}$ heights, the total magnetic field intensity and the gradient of the two sensors were recorded. In order to obtain the local magnetic anomalies, the measured total intensities were reduced by the mean International Geomagnetic Reference Field (IGRF) and filtered to eliminate long-wavelength features. The diurnal variation of the magnetic field was recorded using a second magnetometer (GEM 19-T) at a base station north and beside the landfill. Surface MS was mapped in a 2 by $2 \mathrm{~m}$ grid (2343 measuring spots) using an Explonarium KT-9 susceptibility sensor.

\subsection{Landfill sampling campaign}

A drilling campaign was conducted at the same Austrian MSW landfill and consisted of six drill-sites (Figure 1). For each borehole, several samples of $240 \mathrm{~L}$ were taken at $2 \mathrm{~m}$ depth intervals (Table 3 ). Waste samples from the drillcores were then screened at $40 \mathrm{~mm}$. The resulting sieve overflow ( $>40 \mathrm{~mm}$ ) and underflow ( $<40 \mathrm{~mm}$ ) were manually sorted into twelve material groups as defined in the Austrian Waste Management Plan (Austrian Federal Ministry of Agriculture, 2017), namely: ferrous metals, non-ferrous metals, plastics, paper/paperboard, inert, glass, com- 


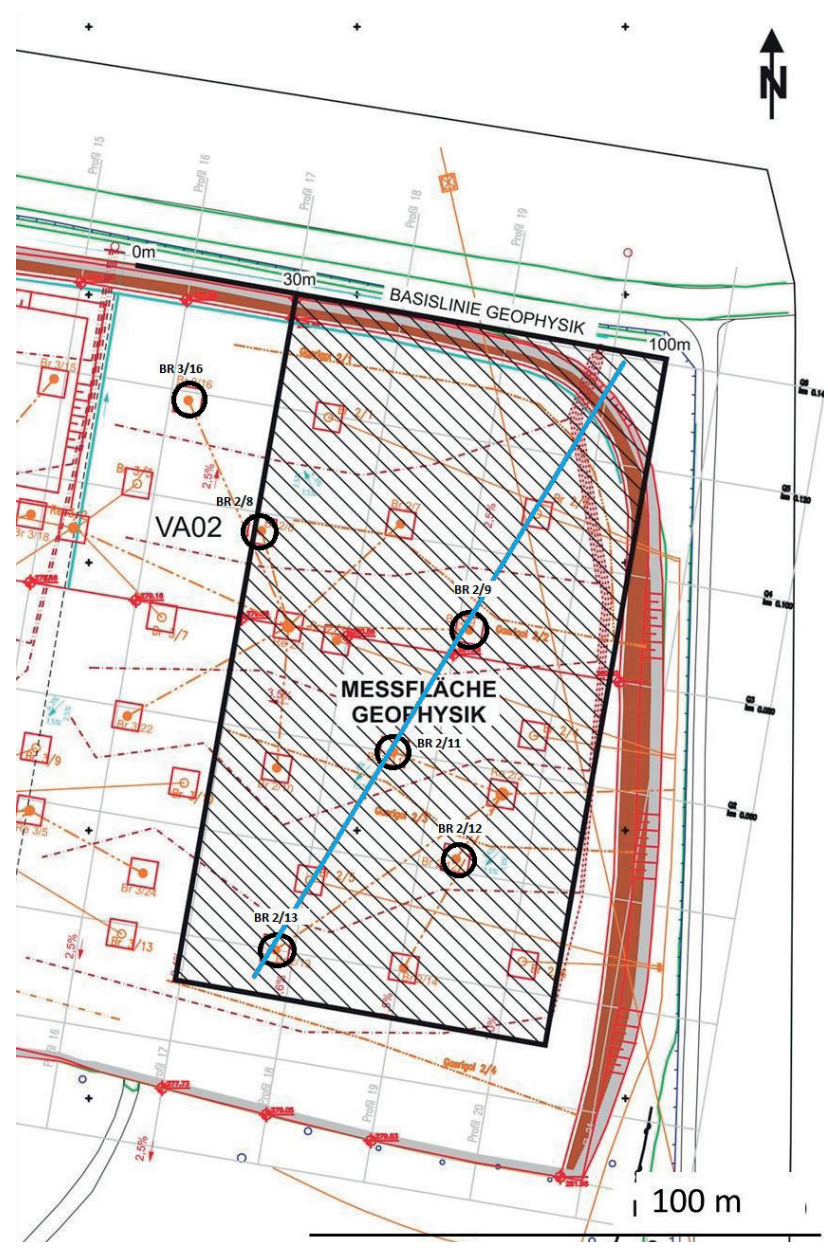

FIGURE 1: Measuring area (black) for magnetic exploration with indication of the profile for inverse modelling (blue), black circles indicate drilling locations.

pounds, problematic substances, wood, textiles, others and sorting residue. Samples from this campaign had been discarded by the time magnetic lab tests were conducted (Chapter 2.1), as such, the waste fractions obtained here by manual sorting are not the same as the samples used for lab tests in chapter 2.1. Finally, the resulting samples were weighed to derive the weight percentage of each fraction.

\subsection{Magnetic Modelling}

Bulk MS values for the investigated landfill material which comprises of individual constituents with distinct intrinsic MS values, were approximated in two ways, (i) from the waste composition, and (ii) deduced from magnetic anomalies.

Firstly, the MS values of individual waste reference samples that were obtained with the MFK1-FA sensor were multiplied by the percentage of individual waste fractions according to manual sorting of landfilled waste. Thus, the MS value obtained should be representative of the true bulk MS value for the excavated material and be directly comparable with the MS values derived from magnetic anomalies. Some approximations were used, in particular, the MS value for $\mathrm{Cu}$ scrap was used to represent the entire non-ferrous metal fraction, the $P E$ reference sample was used for
TABLE 3: Samples from drilling used for manual sorting.

\begin{tabular}{l|c|c}
\hline Borehole & Depth [m] & Number of samples \\
\hline BR 3/16 & 7.70 & 3 \\
\hline BR 2/8 & 15.20 & 7 \\
\hline BR 2/11 & 17.20 & 8 \\
\hline BR 2/12 & 12.40 & 5 \\
\hline BR 2/13 & 10.40 & 4 \\
\hdashline BR 2/9 & 11.30 & 5 \\
\hline Sum & & 32 \\
\hline
\end{tabular}

the plastics fraction, a value for quartz sand was used for the glass and the inert fractions, and for composite materials a value of $3.54 \times 10^{-5} \mathrm{SI}$ was used. This last value was derived from the composition of $75 \%$ paper, $20 \% \mathrm{PE}$ and $5 \%$ aluminium (Al). The MS value for $\mathrm{Al}$ was taken from (Nave, 2019) and the MS value for potting soil was used for the sorting residue. For the water content, a MS value of 8.72 $x 10^{-6} \mathrm{SI}$ was used. Problematic materials (e.g. batteries, syringes etc.) and other materials were not considered.

Secondly, magnetic anomalies observed in the field survey were used to model the bulk MS values for distinct prismatic bodies along a profile (Figure 1) using POTENT software from Geophysical Software Solutions Pty. Limited (Australia). Estimating bulk MS of distinct volumes simplifies the problem that within landfills, not all objects present can be resolved by inverse modelling. This is due to the abundance of different objects within the landfill. Reduced magnetic anomaly values were inverted without contributions from remanent magnetization and a geological background susceptibility of $5 \times 10^{-4} \mathrm{SI}$. The Earth's induced magnetic field was set to that of the IGRF field at the time of the data acquisition, namely $48591 \mathrm{nT}$ with a declination of $4^{\circ}$ and an inclination of $65^{\circ}$.

The two approaches, prediction from waste composition, and inversion from magnetic anomalies, yielded different MS values. The bulk MS of the waste mixture is dominated by the MS of iron, as the MS of other materials is negligable (Table 1). Furthermore, the MS of iron is not constant. Thus, we investigated what intrinsic MS value for iron would yield a bulk MS value that corresponds to the MS modelled from measured magnetic anomalies of the MSW.

\section{RESULTS AND DISCUSSION}

\subsection{Magnetic Lab Tests}

The MS values of waste reference samples are summarized in Figure 2 for all sensors. In Table 4, data from the MFK1-FA sensor is listed separately. Sample statistics suggest that the data are not normally distributed, thus, median and quartile values are given.

The MS laboratory results are considered reliable as measurements of the MS2 sensor were generally in agreement with those of the MFK1-FA sensor. However, measurements with the MS2 sensor yielded several outliers. Values obtained by the MFK1-FA sensor were used for the prediction of the magnetic anomalies in chapter 3.2.

It was expected that positive outliers for one $\mathrm{KS}$, one 


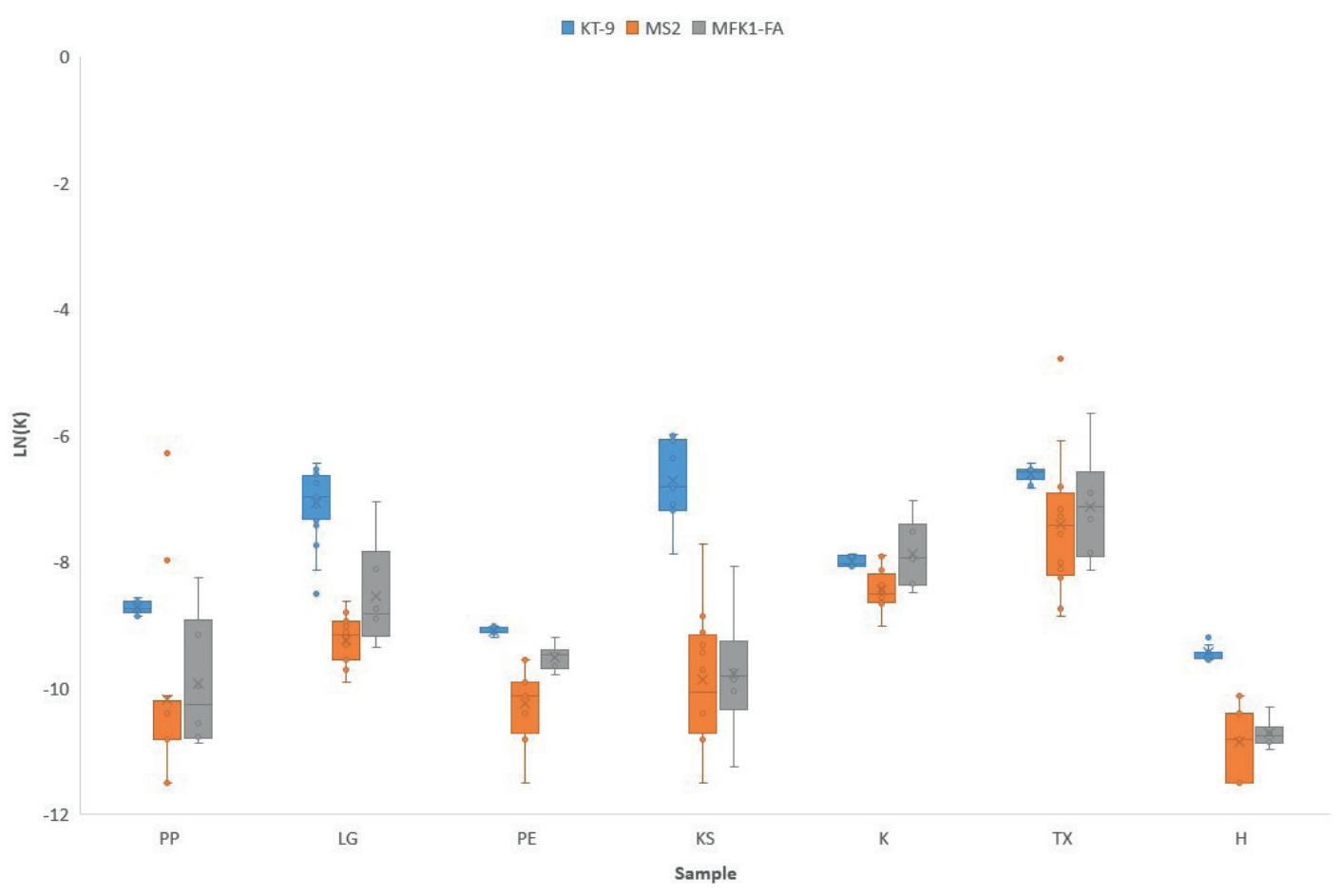

FIGURE 2: Magnetic susceptibility of reference samples.

TX and one PP sample were due to contamination by magnetic particles. This was confirmed by their removal using a hand magnet and subsequent re-measurement. For PET, $\mathrm{Cu}$ and $\mathrm{Fe}$, the MS values were below and above the technical measuring range of the Exploranium KT-9 and Bartington MS2 sensors, respectively. The magnetic susceptibility in all quartz sand measurements, and 10 of the 12 potting soil measurements, were below $-2.10 \times 10^{5} \mathrm{SI}$ and within the measurement uncertainty of the Bartington MS2 sensor. These data are therefore not shown. The measured MS values of $\mathrm{Fe}$ and $\mathrm{Cu}$ were above the measuring range of the KLF-3 Minikappa and Agico MFK1-FA sensors.

Magnetic susceptibility is a frequency dependent quantity. Frequency dependence of magnetic susceptibility is defined as the percentage deviation between the suscep- tibility at 3904 and $976 \mathrm{~Hz}$. This dependence was in the range of $4 \%$ for all measurements, which is far below the variation within each material group.

The NRM of individual materials shows large variations within each material group. For most materials the median values are between 0.02 and $0.42 \mathrm{SI}$. We found deviations from this range only for shredded bottle lids (NRM $=1.56$ - $10^{-4} \mathrm{SI}$ ) and quartz sand (NRM = 4.05 $\cdot 10^{-4} \mathrm{SI}$ ) (Figure 3 , Figure 5). Cu shows values in the same order of magnitude as the remaining non-metallic materials. Fe shows values located at the higher end of the spread, but not significantly higher than values derived for paper and textiles, which were expected to be significantly lower. No clear correlation between NRM and magnetic susceptibility was observed. This is due to the random orientation of grains

TABLE 4: Reference samples for lab tests for the determination of magnetic properties.

\begin{tabular}{|c|c|c|c|}
\hline Sample & Q1 & Median & Q3 \\
\hline K & $2.28 \cdot 10^{-4}$ & $3.56 \cdot 10^{-4}$ & $6.10 \cdot 10^{-4}$ \\
\hline LG & $1.03 \cdot 10^{-4}$ & $1.46 \cdot 10^{-4}$ & $3.89 \cdot 10^{-4}$ \\
\hline $\mathrm{PE}$ & $6.17 \cdot 10^{-5}$ & $7.56 \cdot 10^{-5}$ & $8.23 \cdot 10^{-5}$ \\
\hline PP & $2.03 \cdot 10^{-5}$ & $3.48 \cdot 10^{-5}$ & $1.32 \cdot 10^{-4}$ \\
\hline S & $1.38 \cdot 10^{-6}$ & $2.21 \cdot 10^{-6}$ & $3.30 \cdot 10^{-6}$ \\
\hline $\mathrm{TX}$ & $3.62 \cdot 10^{-4}$ & $8.04 \cdot 10^{-4}$ & $1.40 \cdot 10^{-3}$ \\
\hline $\mathrm{BE}$ & $2.93 \cdot 10^{-5}$ & $3.54 \cdot 10^{-5}$ & $4.31 \cdot 10^{-5}$ \\
\hline $\mathrm{H}$ & $1.87 \cdot 10^{-5}$ & $2.13 \cdot 10^{-5}$ & $2.46 \cdot 10^{-5}$ \\
\hline KS & $3.20 \cdot 10^{-5}$ & $5.52 \cdot 10^{-5}$ & $9.46 \cdot 10^{-5}$ \\
\hline PET & $-1.22 \cdot 10^{-7}$ & $-1.17 \cdot 10^{-6}$ & $-1.07 \cdot 10^{-6}$ \\
\hline FE (calculated from partly filled cubes) & $0.90 \cdot 10^{-1}$ & $9.31 \cdot 10^{-1}$ & $9.61 \cdot 10^{-1}$ \\
\hline CU (calculated from partly filled cubes) & $2.62 \cdot 10^{-4}$ & $3.31 \cdot 10^{-4}$ & $5.52 \cdot 10^{-4}$ \\
\hline
\end{tabular}




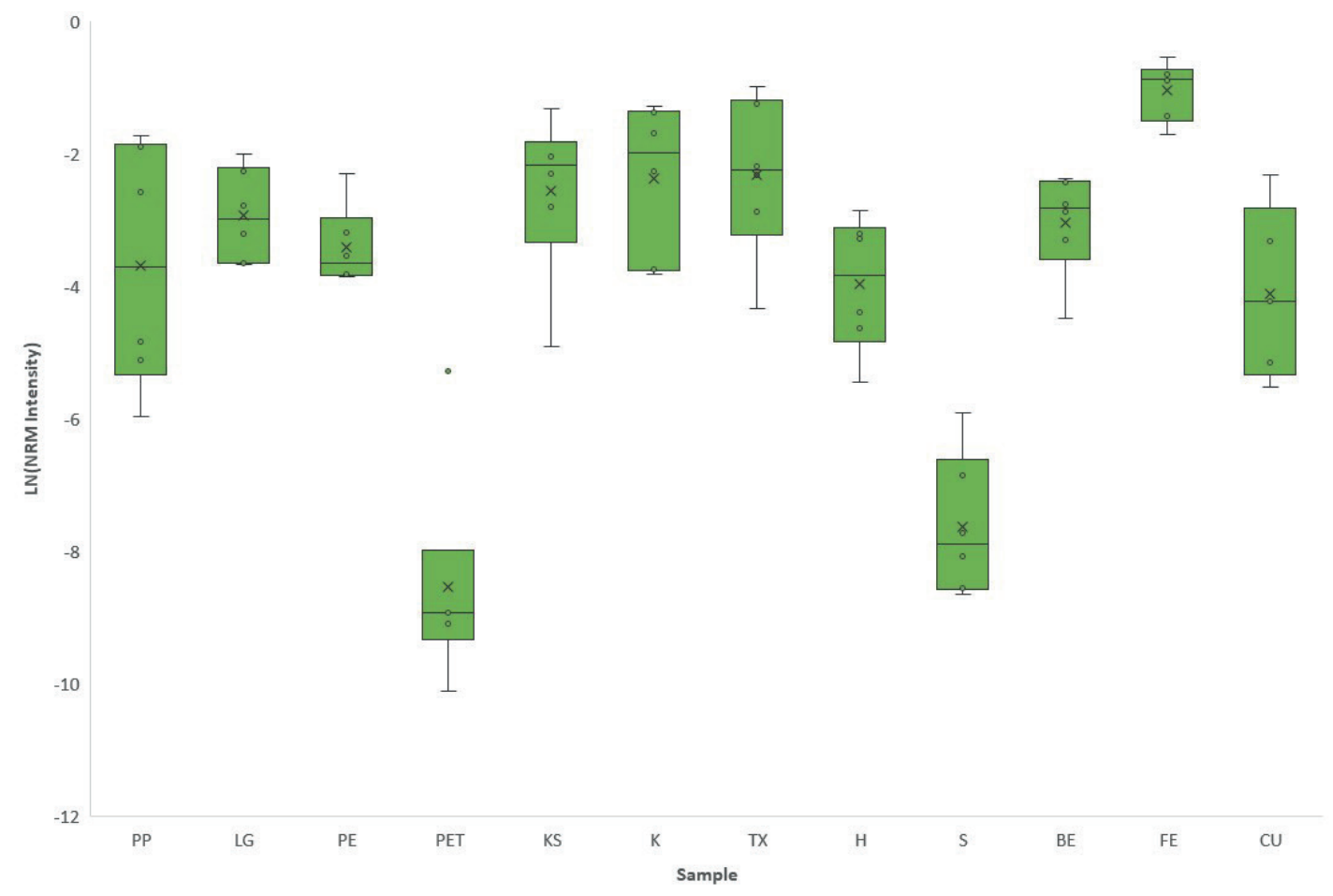

FIGURE 3: Natural remanent magnetization (in $\mathrm{A} / \mathrm{m}$ ) of reference samples.

within the cubes resulting in an overall compensation of remanence.

The VRM of individual reference samples is shown in Table 5. Paper shows a significant VRM, whereas textile samples are characterised by weak viscosity. In all other samples no VRM was observed. The VRM of the paper fraction, and subordinately the textile fraction, might be explained by metallic contaminations attached due to the recycling process.

In contrast to the assumption that remanent magnetization of different pieces levels out in a landfill, most waste samples show mainly remanent and only subordinately induced magnetization, e.g. for paper and paperboard the remanent magnetization is six times higher than the induced magnetization $(Q=6.26)$. The contribution of remanent magnetization to the total magnetization of non-metallic waste fractions can be explained by fine grained iron contaminations. As building sand was neither derived from ELFM, nor from a waste treatment plant, it is believed that no metal contamination is present in this fraction. However, it remains unclear why the building sand shows such strong remanent magnetization.

A comparison of the MS values of waste materials with those of fresh materials (Table 1 ) indicates that the MS of iron scrap $\left(9.31 \cdot 10^{-1}\right)$ is five orders of magnitude lower than the MS for pure iron, two orders of magnitude lower than the MS for martensitic steel, but two orders of magnitude higher than the MS for austenitic steel (Schenck,

TABLE 5: Induced and remanent magnetization of reference samples.

\begin{tabular}{|c|c|c|c|}
\hline Sample & Median Induced Magnetization [A/m] & Median Remanent Magnetization [A/m] & Median Q \\
\hline K & $1.42 \mathrm{E}-02$ & $1.45 \mathrm{E}-01$ & 6.26 \\
\hline LG & $5.84 \mathrm{E}-03$ & $5.16 \mathrm{E}-02$ & 6.19 \\
\hline PE & 3.04E-03 & $2.65 \mathrm{E}-02$ & 10.75 \\
\hline PP & $1.45 \mathrm{E}-03$ & 4.23E-02 & 14.04 \\
\hline S & 8.83E-05 & 4.05E-04 & 6.10 \\
\hline TX & $3.27 \mathrm{E}-02$ & $1.06 \mathrm{E}-01$ & 3.18 \\
\hline $\mathrm{BE}$ & 1.41E-03 & 6.03E-02 & 37.16 \\
\hline $\mathrm{H}$ & 8.48E-04 & 2.50E-02 & 22.41 \\
\hline KS & $2.20 \mathrm{E}-03$ & $1.16 \mathrm{E}-01$ & 36.49 \\
\hline PET & $-4.66 \mathrm{E}-05$ & 1.56E-04 & -3.51 \\
\hline $\mathrm{FE}$ & $3.71 E+01$ & $4.23 \mathrm{E}-01$ & 0.01 \\
\hline $\mathrm{CU}$ & $1.32 \mathrm{E}-02$ & $2.55 \mathrm{E}-02$ & 2.48 \\
\hline
\end{tabular}


1996). Values for fresh and waste $P E$ are in the same order of magnitude. The MS of the PET samples is one order of magnitude higher, and copper scrap and wood samples are two orders of magnitude higher than that of pure materials.

\subsection{Magnetic Landfill Explorations}

The magnetic anomaly map (Figure 4) shows several positive and negative anomalies in the order of $1000 \mathrm{nT}$. The anomalous areas might represent Fe enrichments. However, these could not be confirmed as no boreholes were drilled there.

The vertical gradient of the total intensity of the Earth's magnetic field reveals strong positive anomalies in the east and strong negative anomalies in the north (Figure 5). These can be interpreted as polarised near-surface metal pieces. The positive and negative sign of the anomalies, respectively, mean a normal and reverse alignment of the remanent magnetic field inside the iron pieces. These results suggest there are near-surface iron pieces in borehole BR
$2 / 8$, which could not be verified by the drilling campaign as the uppermost sample was taken at a depth of $2 \mathrm{~m}$. The high susceptibility of near surface iron pieces can be an additional explanation for the magnetic anomaly in the area of borehole BR 2/8.

Magnetic susceptibility data for the upper five centimeters (Explonarium sensor), indicates that the landfilled construction and demolition (C\&D) waste contains partial enrichments of iron, whereas other areas at the surface are free of iron (Figure 6). This was confirmed by macroscopic observations, i.e. the presence of metal objects, at certain spots of the landfill surface. The corresponding smallscale magnetic anomalies especially occur in the area around bore hole BR 2/12 where also metal enrichments were found at the surface.

\subsection{Waste Characterisation}

Material composition of 32 samples taken at different locations and depths at the MSW landfill indicate an aver-

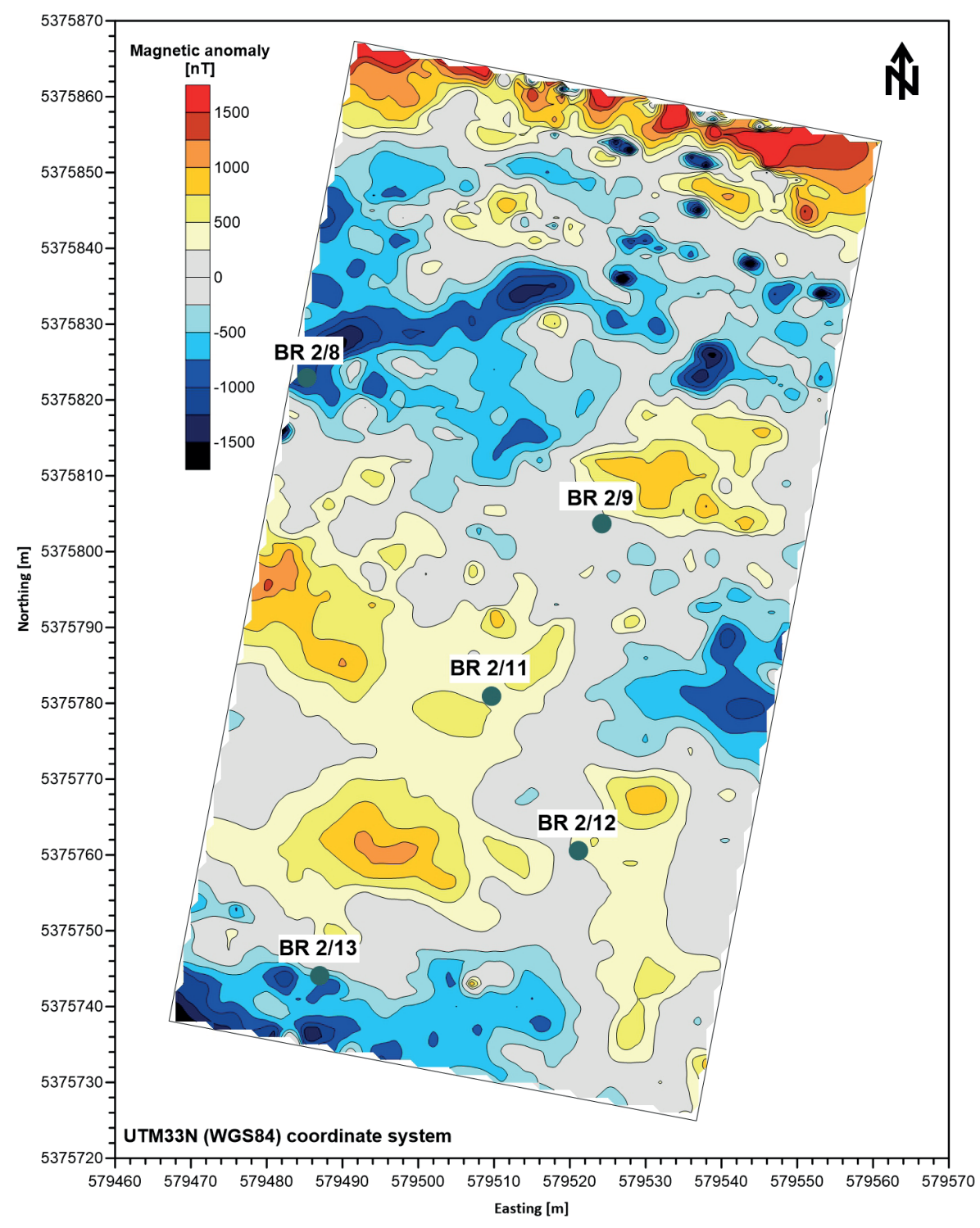

FIGURE 4: Magnetic anomalies at an Austrian landfill (lower sensor = $1 \mathrm{~m}$ above ground). 


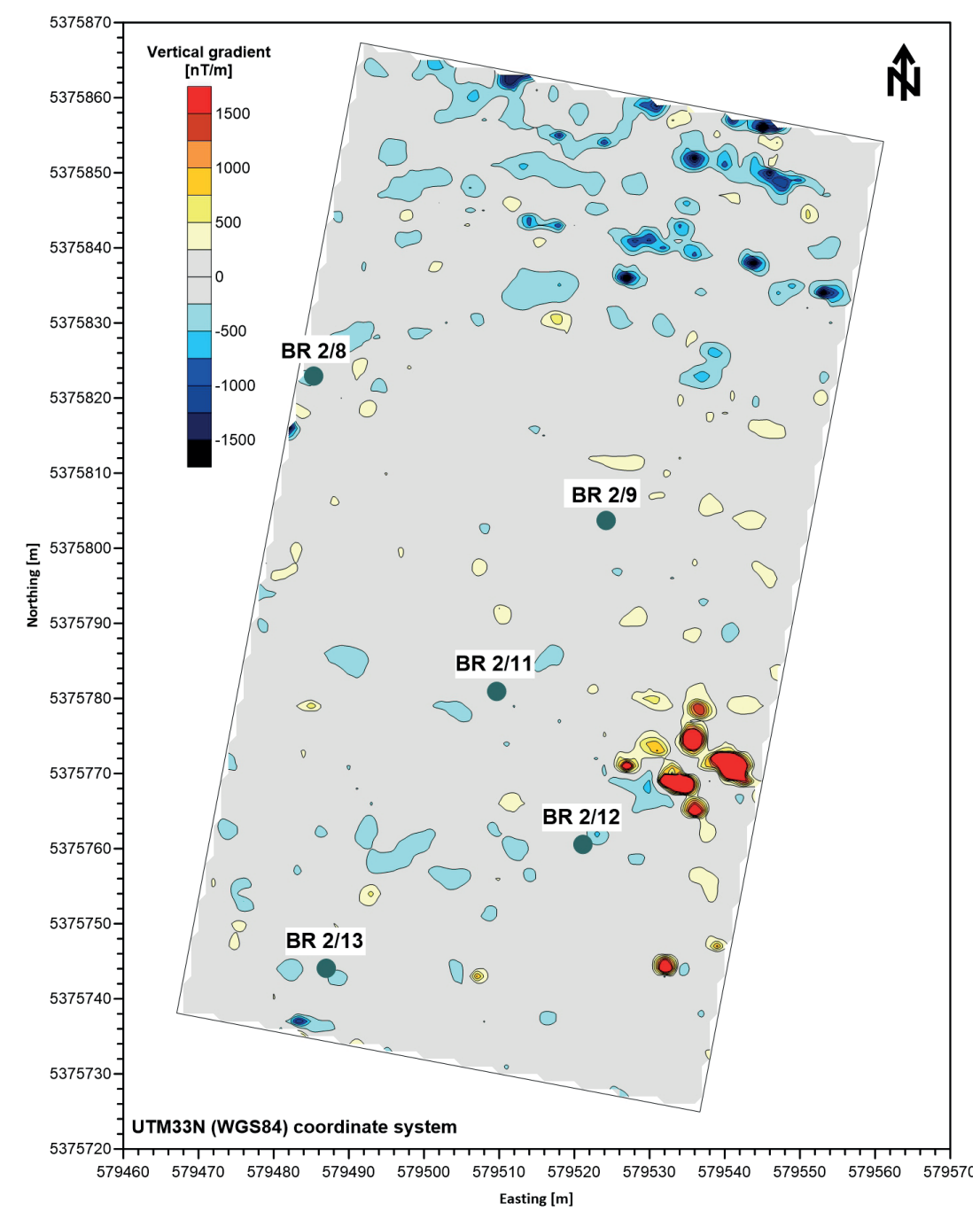

FIGURE 5: Vertical gradient of the total magnetic field at an Austrian landfill.

age composition (incl. water) of $42.2 \pm 5.8$ wt.\% water, 26.2 \pm 8.4 wt. $\%$ sorting residue, $10.7 \pm 4.2 \mathrm{wt}$. $\%$ plastics, $5.8 \pm$ 3.2 wt. $\%$ wood, $3.5 \pm 2.6$ wt. $\%$ textiles, $3.2 \pm 1.2$ wt. $\%$ inerts, $2.3 \pm 1.4$ wt. $\%$ iron, $2.2 \pm 2.2$ wt.\% compounds, $2.0 \pm 2.0$ wt.\% paper and paperboard, $0.6 \pm 0.4$ wt. $\%$ glass, $0.6 \pm 0.4$ wt. $\%$ nonferrous metals, $0.1 \pm 0.1$ wt. $\%$ problematic substances and $0.9 \pm 0.7$ wt. $\%$ others. No correlation between iron content and depth was found, although a metal enrichment in larger depths was expected due to worse waste separation in earlier times. Data for individual boreholes is shown in Figures 7a-c. According to the determined waste compositions, the bulk MS values for the individual waste samples are expected in the range of 0.01 to $0.05 \mathrm{SI}$.

\subsection{Magnetic Modelling}

Using MS values of the reference samples and the material composition of individual samples from the Austrian MSW landfill, a linear relationship between the iron content and the magnetic susceptibility value of samples was found. This relation predicts MS values for mixed MSW of 0.01 to $0.05 \mathrm{SI}$ with iron contents between 1 and $5 \mathrm{wt}$.\%. However, as the average MS value of iron might be higher for iron pieces in the landfill than that of the reference sample, the effect of different MS values for iron, i.e. $0.931 \mathrm{SI}$ and $5 \mathrm{SI}$, has on the predicted iron content is demonstrated (Figure 8).

Subsequently, the measured total magnetic intensity along profile 1 was modelled using prismatic bodies with varying MS values (Figure 9). The model suggests that the MS of each body ( 0.06 to $0.11 \mathrm{SI}$ ) is significantly higher than the expected geologic background MS. Furthermore, areas of higher $(\geq 0.10 \mathrm{SI})$ and lower susceptibility $(\leq 0.08$ $\mathrm{SI})$ can be identified. These areas are assumed to correlate with higher and lower iron contents, respectively. The trend between the two drill cores along the modelled profile, i.e. BR 2/11 (modelled MS $=0.10 \mathrm{SI}$, average iron content 4.1 wt. \% dry matter) and BR 2/9 (modelled MS $=0.075$ SI, average iron content 3.9 wt.\% dry matter), speculatively might support this assumption. In the southwest of the landfill we see an area with a MS close to zero, and just beside an area with increased MS. The different heights of the columns with respect to the landfill surface might contain information about the presence or absence of near-surface iron pieces. 


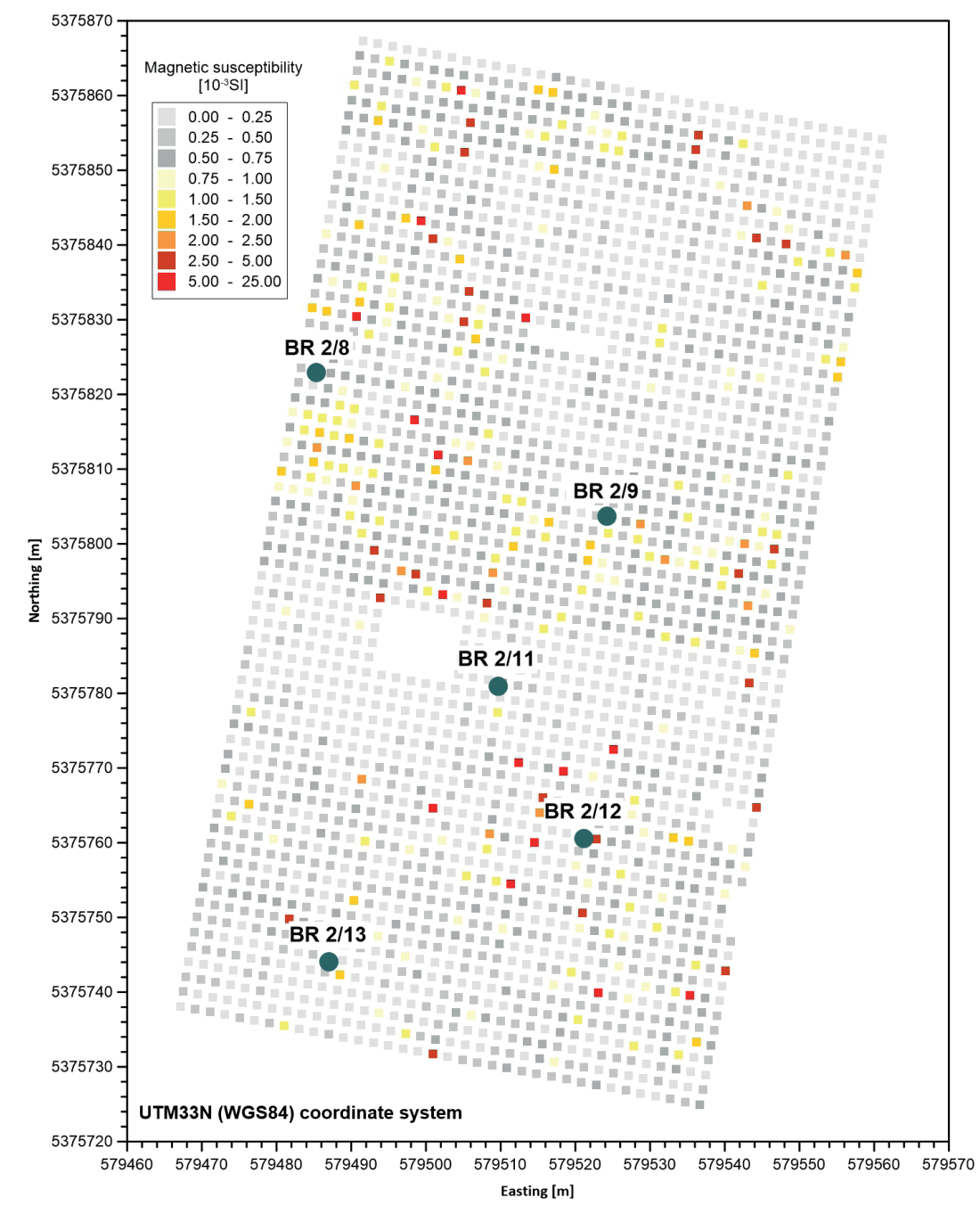

FIGURE 6: Magnetic surface susceptibility at an Austrian landfill.

A comparison between the two approaches, i.e. prediction from waste composition, and inversion from magnetic anomalies, demonstrates that of MS estimation results reveals that MS values derived from magnetic surveying data (0.06-0.11 SI) are higher than those derived from laboratory measurements of reference samples (0.01-0.05 SI). This might be explained by differences in MS of individual iron alloys. Consequently, a multiplication of magnetic data and iron content was used to estimate the magnetic susceptibility of the landfilled iron scrap, and is in the range of $5 \mathrm{SI}$ (Figure 10).

\section{CONCLUSIONS}

In this study we investigated two research questions, (i) for material recovery, to which degree do the MS values of defined materials differ from those corresponding to respective waste fractions, and (ii) can laboratory measurements of the MS of (mixtures of) individual waste fractions be related to the total field magnetic measurements on site, and can the combination of laboratory and field measurements predict the iron content of a landfill?.

In order to answer research question (i), we conduct- ed MS analyses on reference samples, mainly produced by mechanical processing of MSW and compared them to literature values for virgin materials. To answer research question (ii), we measured the total magnetic intensity at an Austrian MSW landfill and inverted the data to obtain the MS of the buried waste. Afterwards, we took samples by drilling and manually sorted the samples. Then we calculated the MS of the obtained waste mixtures which would be expected from the MS values determined for the reference samples. The latter are representative of individual waste fractions. Finally, we compared the expected MS and the MS obtained from inversion of magnetic anomalous data.

Regarding research question (i), MS values of individual waste materials could be reproduced in repeated measurements, showing significant variations within each material fraction. As profound knowledge of the possible variation is crucial to the reliable interpretation of landfill magnetic anomalies, further research on magnetic waste properties is needed. The impact of metallic defilements, which remained even after removal by a magnet, was investigated by comparing the MS values of virgin materials and waste fractions. MS values for virgin and waste $P E$ are in the same range, for almost all other fractions, the 
BR 3/16

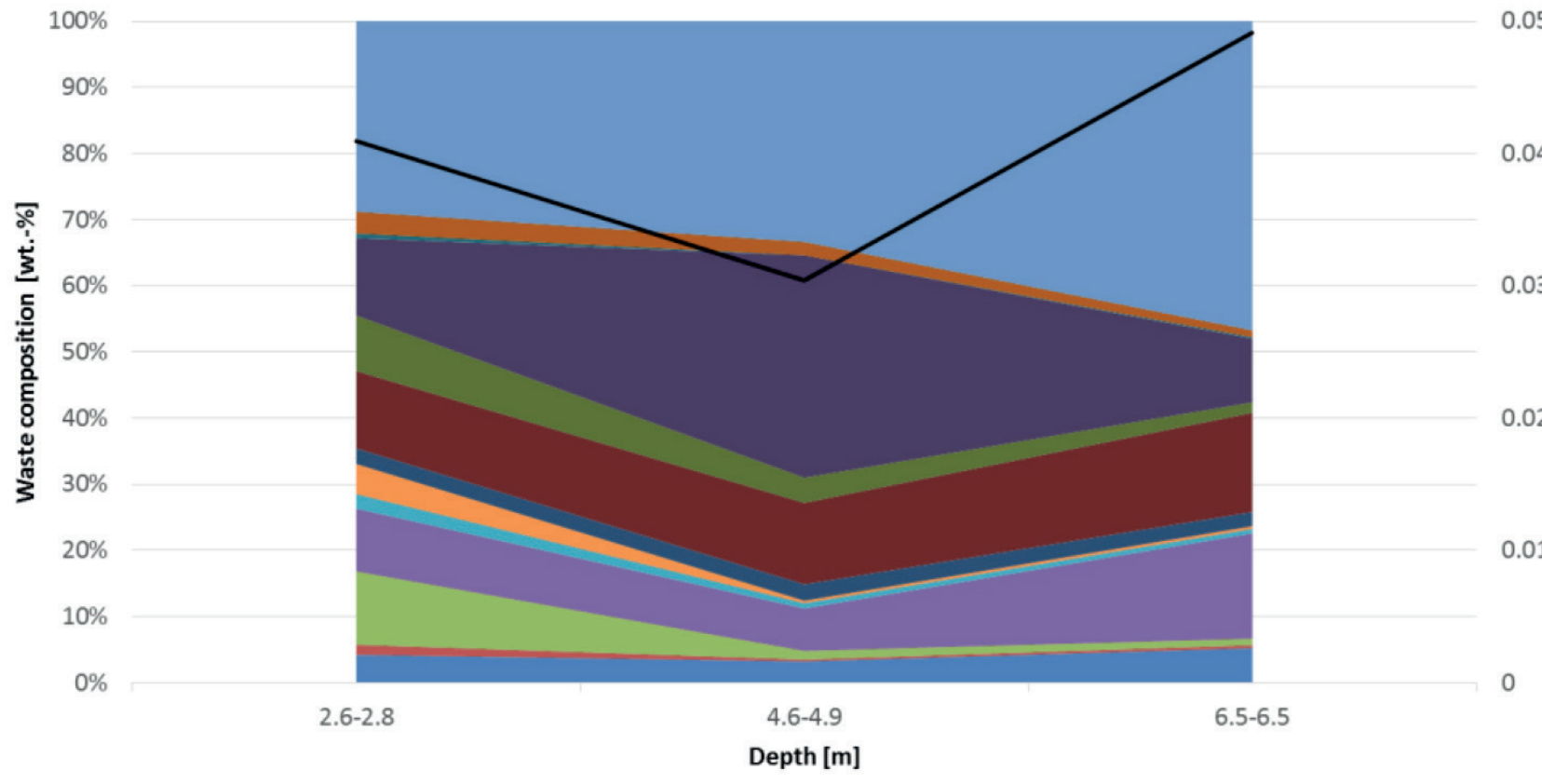

\begin{tabular}{|c|c|c|c|c|}
\hline $\begin{array}{l}\text { Iron } \\
\text { Compounds }\end{array}$ & $\begin{array}{l}\text { Nonferrous Metals } \\
\text { Inert Materials }\end{array}$ & $\begin{array}{l}\text { Paper \& Paperboard } \\
\text { Wood }\end{array}$ & $\begin{array}{l}\text { Plastics } \\
\text { Textiles }\end{array}$ & $\begin{array}{l}\text { Glass } \\
\text { Sorting Residue }\end{array}$ \\
\hline blematic Substances & Other & Water & _Magnetic Susceptibility & \\
\hline
\end{tabular}

BR 2/8

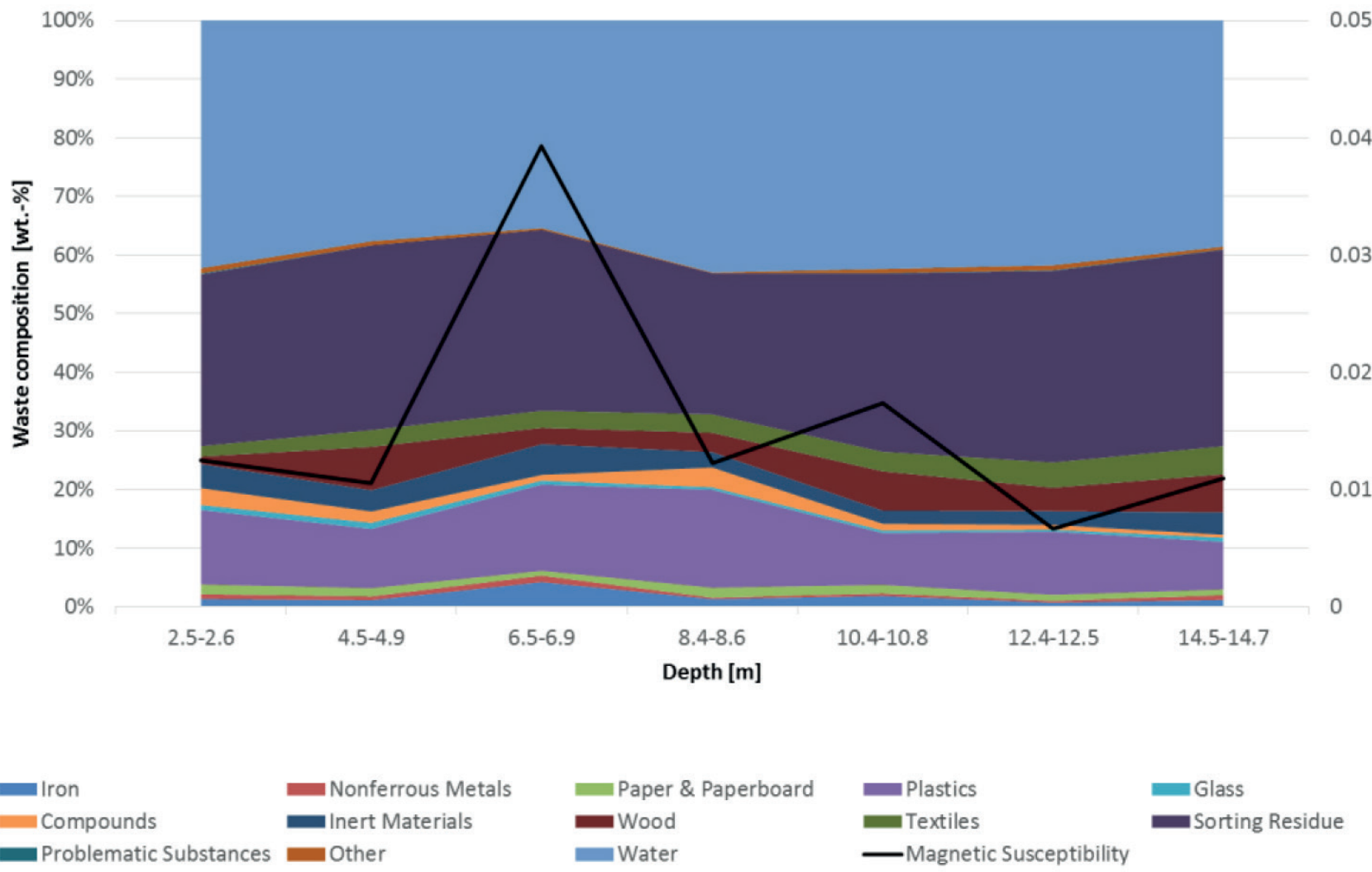

FIGURE 7a: Waste composition and predicted magnetic susceptibilities calculated from lab values for individual waste fractions at bore holes 3/16 and 2/8 at an Austrian landfill. 
BR 2/11

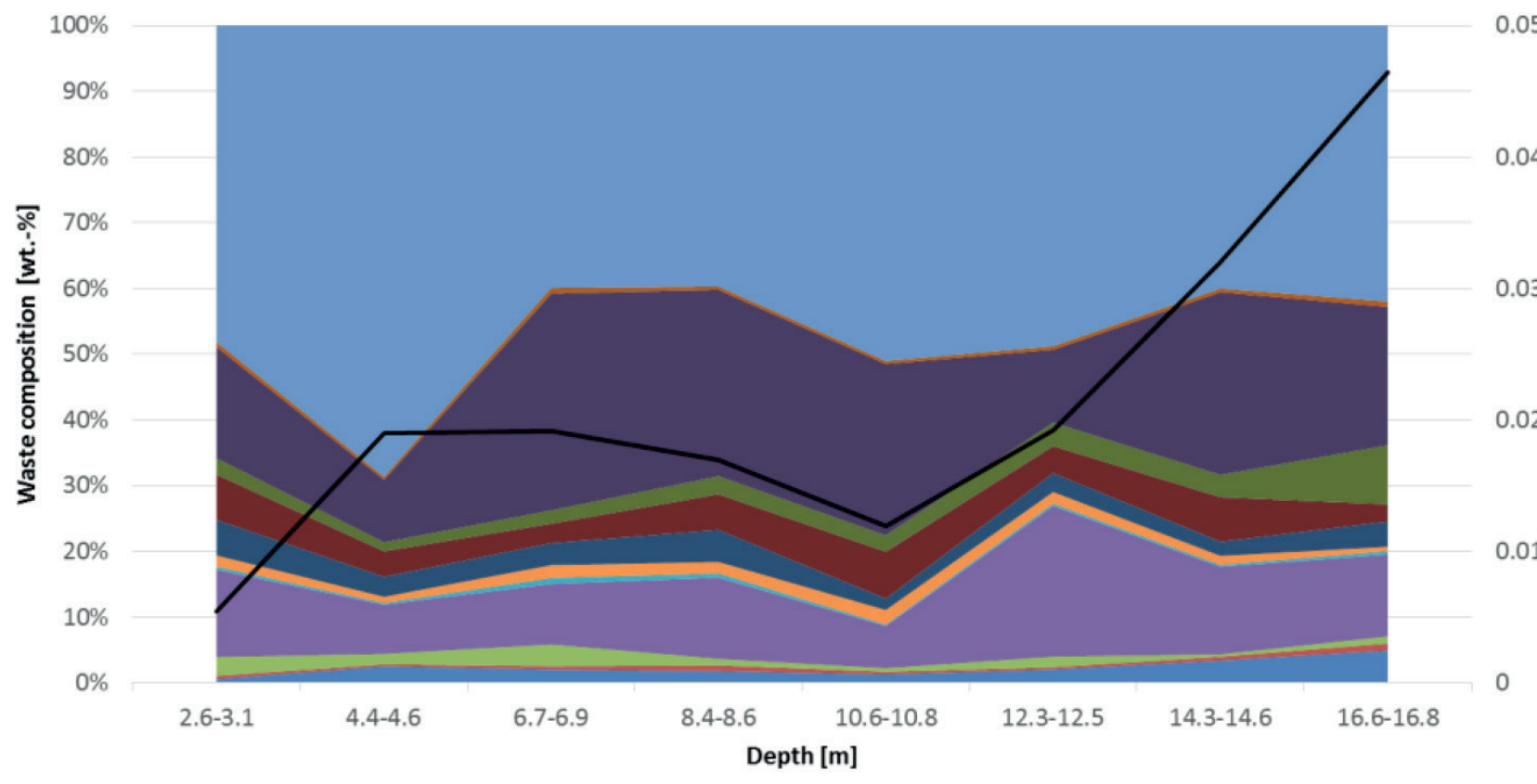

\begin{tabular}{|c|c|c|c|c|}
\hline $\begin{array}{l}\text { Iron } \\
\text { Compounds }\end{array}$ & $\begin{array}{l}\text { Nonferrous Metals } \\
\text { Inert Materials }\end{array}$ & $\begin{array}{l}\text { Paper \& Paperboard } \\
\text { Wood }\end{array}$ & $\begin{array}{l}\text { Plastics } \\
\text { Textiles }\end{array}$ & $\begin{array}{l}\text { Glass } \\
\text { Sorting Residue }\end{array}$ \\
\hline tic Substances & Other & Water & _Magnetic Susceptibility & \\
\hline
\end{tabular}

BR 2/12

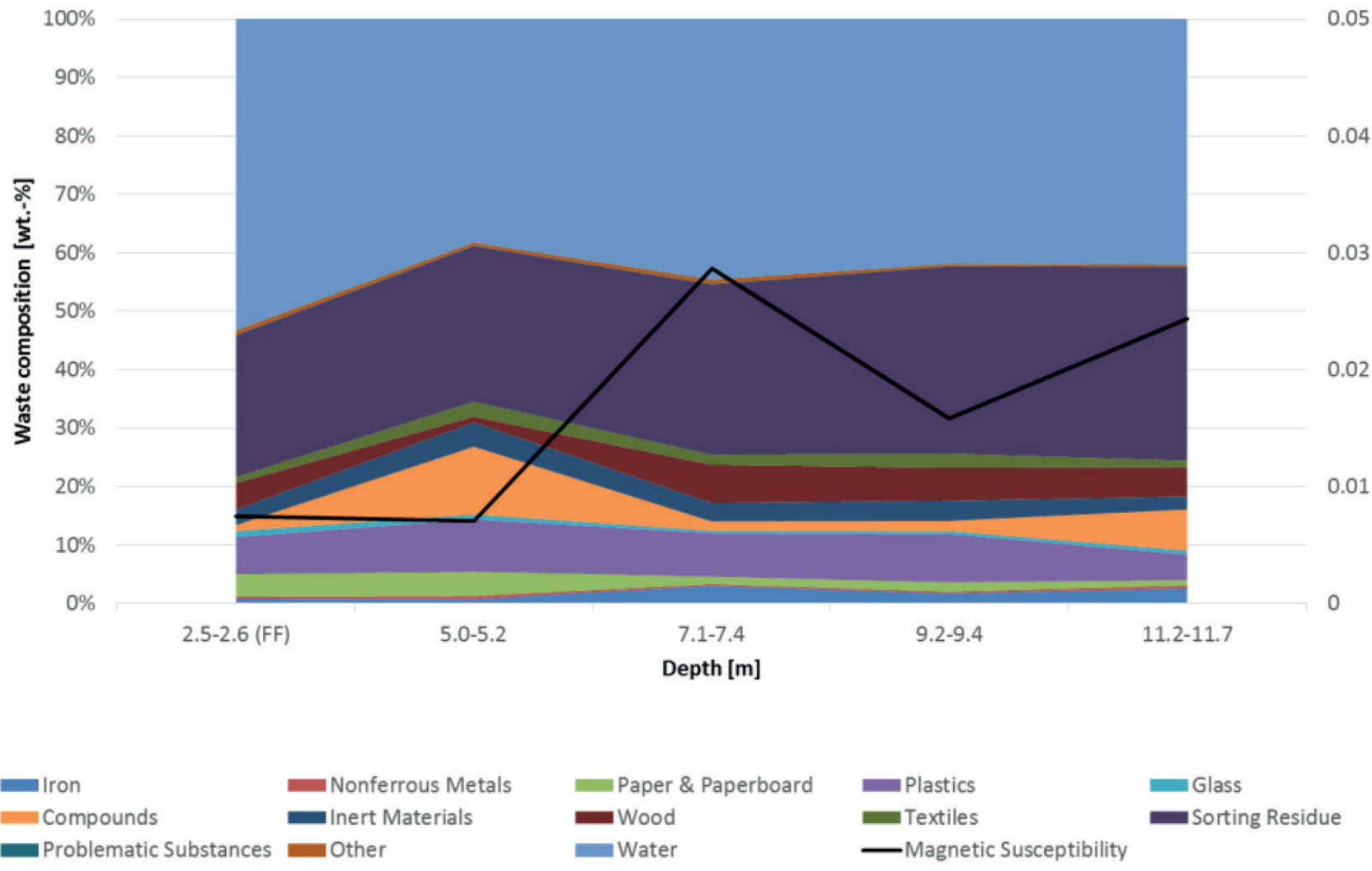

FIGURE 7b: Waste composition and predicted magnetic susceptibilities calculated from lab values for individual waste fractions at bore holes 2/11 and 2/12 at an Austrian landfill. 
BR 2/13

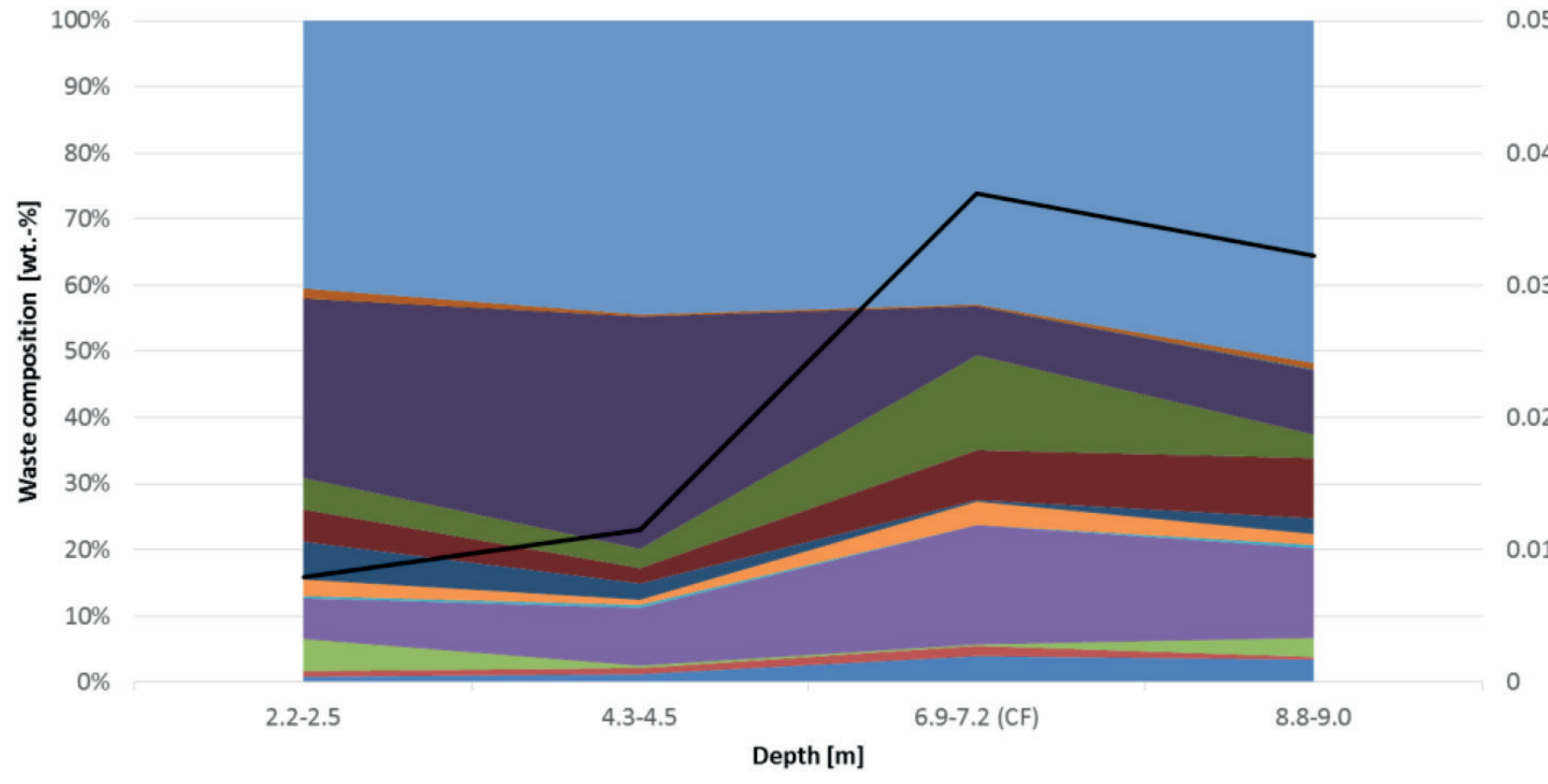

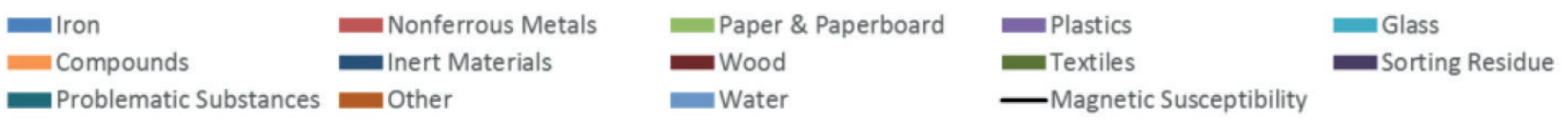

BR 2/9

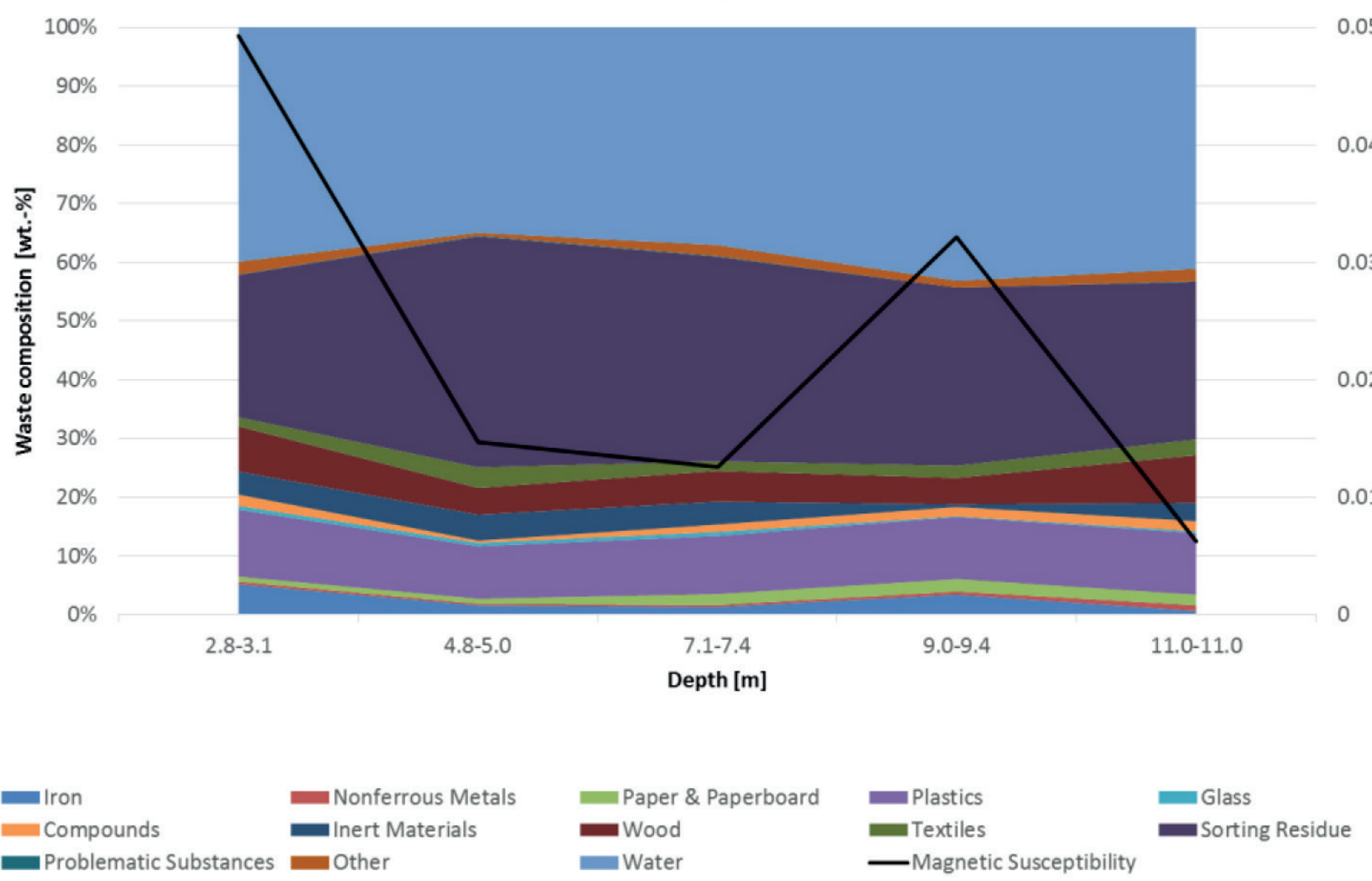

FIGURE 7c: Waste composition and predicted magnetic susceptibilities calculated from lab values for individual waste fractions at bore holes 2/13 and 2/9 at an Austrian landfill. 


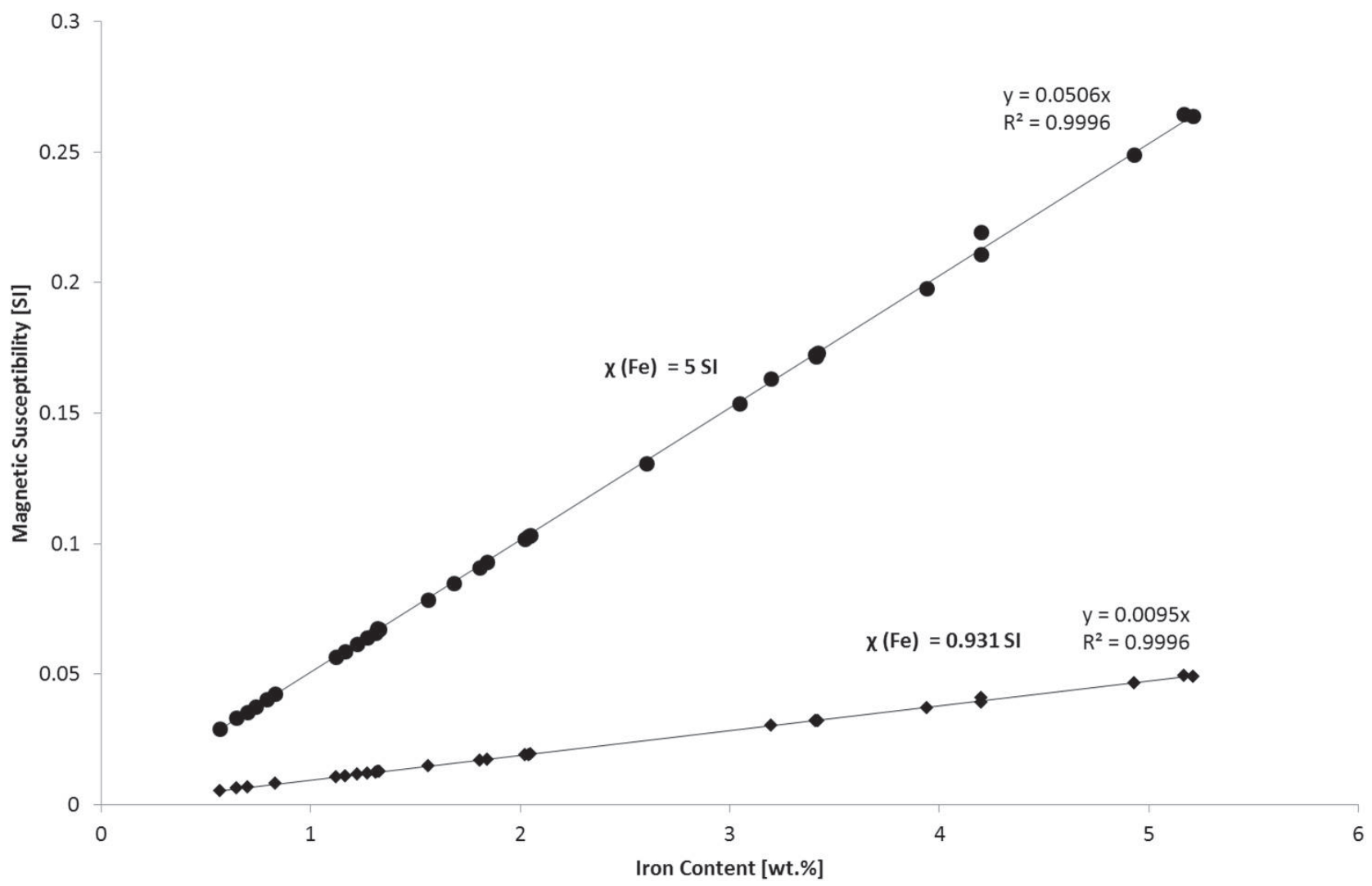

FIGURE 8: Predicted magnetic susceptibility of waste mixtures for $x(\mathrm{Fe})=0.931 \mathrm{SI}$ (from lab measurements) and $x(\mathrm{Fe})=5 \mathrm{SI}$.

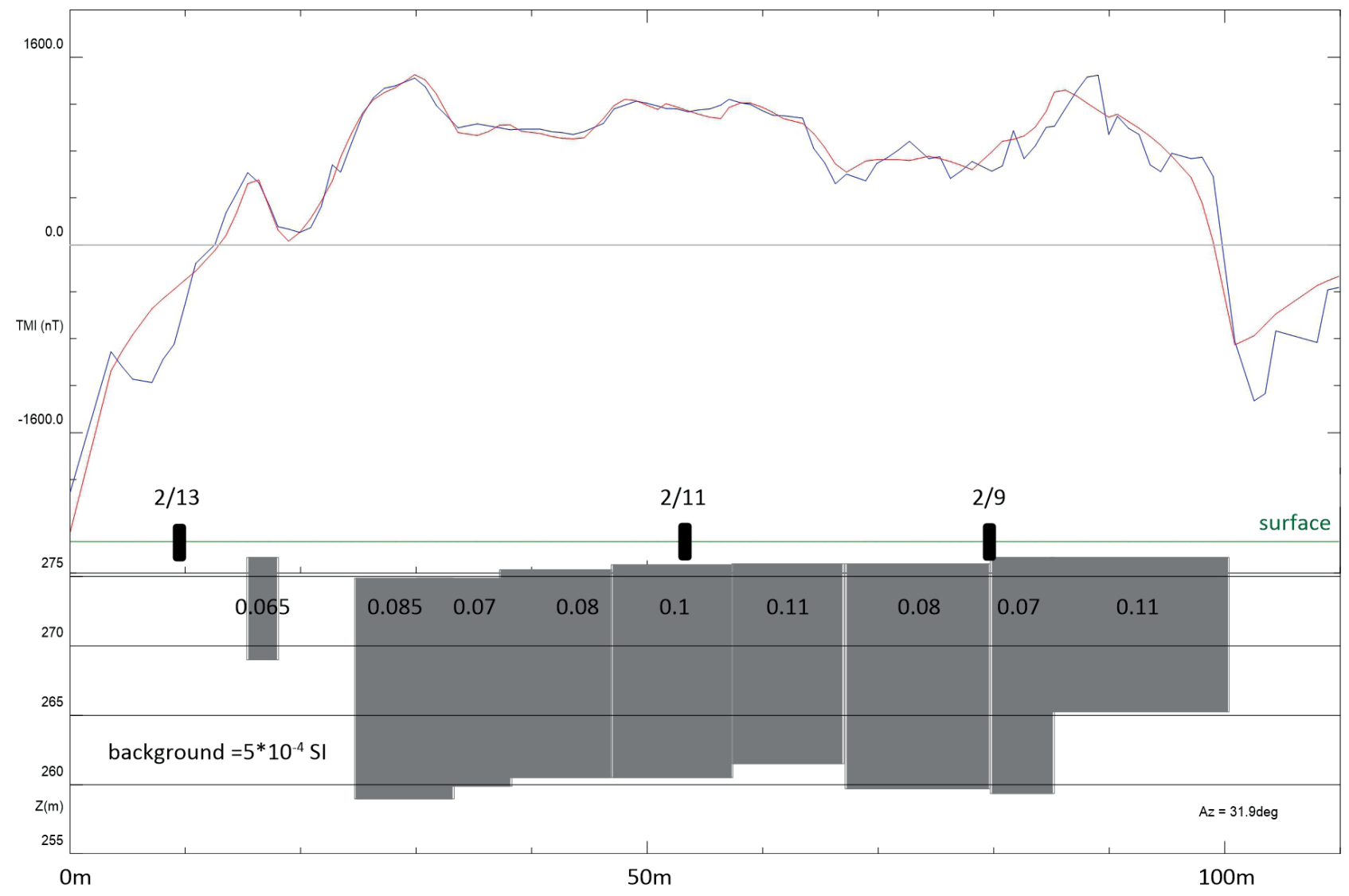

FIGURE 9: Magnetic susceptibility of the investigated MSW landfill, modelled from the total magnetic intensity. 


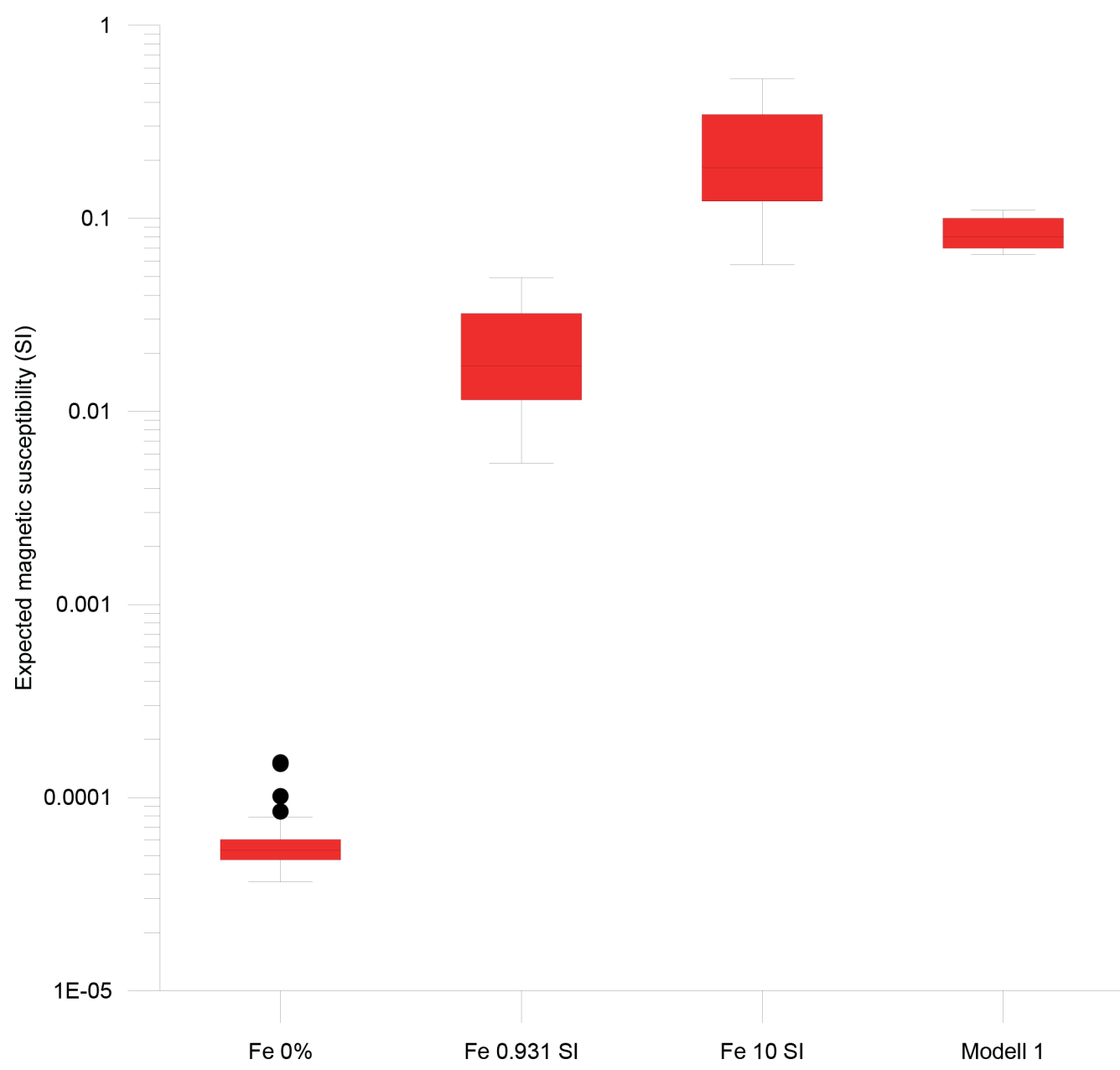

FIGURE 10: Expected magnetic susceptibility of a landfill without iron and with those amounts of iron obtained by manual sorting at the Austrian landfill for different magnetic susceptibilities of iron.

MS values for virgin materials and the respective waste fractions differed. For example, for PET MS values are one order, and for copper scrap and wood samples even two orders of magnitude above the MS values for virgin materials.

Regarding research question (ii) it was found that using MS values for the GPI and material composition of landfilled waste yields lower MS values than predicted by modelling magnetic survey data. In the MSW landfill case study, the comparison of the material composition of the samples from the two drill cores along the modelled profile with the bulk MS values from inverse modelling might suggest a rather speculative positive relation. BR $2 / 11$ showed modelled MS of $0.10 \mathrm{SI}$ and an average iron content of 4.1 wt.\% dry matter, and BR 2/9 showed modelled MS of 0.075 $\mathrm{SI}$, and an average iron content of 3.9 wt.\% dry matter. However, this should be further supported by more extensive experiments.

In summary, it is not straightforward to establish a direct relationship between geophysical magnetic measurements and the iron content of landfilled waste. Modelling this relationship requires additional calibration data obtained from different types of geophysical measurements or prior knowledge on the waste composition.

\section{ACKNOWLED GEMENTS}

The project NEW-MINE has received funding from the European Union's EU Framework Programme for Research and Innovation Horizon 2020 under Grant Agreement No 721185. The project LAMIS has received funding from the Austrian Research Promotion Agency in the Bridge programme under Grant Agreement No 838524. The authors thank Andrew Greenwood, $\mathrm{PhD}$, for his excellent language revision.

\section{REFERENCES}

Austrian Federal Ministry of Agriculture, F. E. (2017). Federal Waste Management Plan.

Bavusi, M., Rizzo, E., \& Lapenna, V. (2006). Electromagnetic methods to characterize the Savoia di Lucania waste dump (Southern Italy). Environmental Geology, 51, pp. 301-308.

Bernstone, C., Dahlin, T., Ohlsson, T., \& Hogland, W. (2000). DC-resistivity mapping of internal landfill structures: two pre-excavation surveys. Environmental Geology, 39(3-4), pp. 360-371.

Bobe, C., Van De Vijver, E., \& Van Meirvenne, M. (2018). Exploring the potential of electromagnetic surface measurements for the characterisation of industrial landfills. Proceedings of the 4th International Academic Symposium on Enhanced Landfill Mining (ELFM IV), (pp. 45-50). Mechelen.

Burnley, S. (2007). A review of municipal solid waste composition in the United Kingdo. Waste Management, 27(10), pp. 1274-1285. 
Cardarelli, E., \& di Filippo, G. (2004). Integrated geophysical surveys on waste dumps: evaluation of physical parameters to characterize an urban waste dump (four cases studies in Italy). Waste Management and Research, 22, pp. 390-402.

di Maio, R., Fais, S., Ligas, P., Piegari, E., Raga, R., \& Cossu, R. (2018). 3D geophysical imaging for site-specific characterization plan of an old landfill. Waste Management, 76, pp. 629-642.

Dobrin, M., \& Savit, H. (1960). Introduction to Geophysical Prospecting. New York: McGraw Hill.

Dumont, G., Robert, T., Marck, N., \& Nguyen, F. (2017). Assessment of multiple geophysical techniques for the characterization of municipal waste deposit sites. Journal of Applied Geophysics, 145, pp. 74-83.

Fettweis, G., Brandstätter, W., \& Hruschka, F. (1985). Was ist Lagerstättenbonität? Mitteilungen der Österreichischen Geologischen Gesellschaft, 78, pp. 23-40

García López, C., Ni, A., Hernández Parrodi, J., Pretz, T., Raulf, K., \& Küppers, B. (2019). Characterization of landfill mining material after ballistic separation to evaluate material and energy recovery potential. Volume 08 - December 2019, Detritus - Multidisciplinary Journal for Waste Resources and residues.

Grellier, S., Reddy, K., Gangathulasi, J., Adib, R., \& Peters, C. (2007). Correlation between Electrical Resistivity and Moisture Content of Municipal Solid Waste in Bioreactor Landfill. Geoenvironmental Engineering, 226(11), pp. 1-14

Hermozilha, H., Grangeia, C., \& Senos Matias, M. (2010). An integrated 3D constant offset GPR and resistivity survey on a sealed landfill Ilhavo, NW Portugal. Journal of Applied Geophysics, 70, pp. 58-71.

Hernández Parrodi, J. C., Höllen, D., \& Pomberger, R. (2018). Characterization of Fine Fractions from Landfill Mining: A Review of Previous Investigations. Detritus, 2, pp. $46-62$.

Jones, P., Geysen, D., Tielemans, Y., van Passel, S., Pontikes, Y., Blanpain, B., . . . Hoekstra, N. (2013). Enhanced Landfill Mining in view of multiple resource recovery: a critical review. Journal of Cleaner Production, 55, pp. 45-55.

Knödel, K., Krummel, H., \& Lange, G. (2005). Handbuch zur Erkundung des Untergrundes von Deponien und Altlasten (Vol. 3). Berlin, Heidelberg: Springer.

Krook, J., Svensson, N., \& Eklund, M. (2012). Landfill mining: A critical review of two decades of research. Waste Management, 32, pp. 513-520

Leikam, K., \& Stegmann, R. (1999). Influence of mechanical-biological pretreatment of municipal solid waste on landfill behaviour. Waste Management \& Research, 17, pp. 424-429.

Lin, S., \& Chang, C. (2000). Treatment of landfill leachate by combined electro-Fenton oxidation and sequencing batch reactor method. Water Research, 34(17), pp. 4243-4249.

McCann, D. (1994). Geophysical methods for the assessment of landfill and waste disposal sites: a review. Land Contamination and Reclamation, 2, pp. 73-83.

Meju, M. (2000). Geoelectrical investigation of old/abandoned, covered landfill sites in urban areas: model development with a genetic diagnosis approach. Journal of Applied Geophysics, 44, pp. 115-150.

Mor, S., Ravindra, K., de Visscher, A., Dahiya, R., \& Chandra, A. (2006) Municipal solid waste characterization and its assessment for potential methane generation: A case study. Science of the Total Environment(371), pp. 1-10.

Muras, A., Küppers, B., Höllen, D., \& Rothschedl, R. (2018). Landfill Mining of a Mixed Municipal Solid Waste and Commercial Waste Landfill: Application of Existing Processing Technology - Opportunities and Limitations. 4th International Symposium on Enhanced Landfill Mining (ELFM IV).
Nave, C. (2019, 5 29). HyperPhysics. Retrieved from http://hyperphysics.phy-astr.gsu.edu/hbase/Solids/magpr.html

Orlando, L., \& Marchesi, E. (2001). Georadar as a tool to identify and characterise solid waste dump deposits. Journal of Applied Geophysics, 48, pp. 163-174

Phaovibul, O., Loboda-Cackovic, J., Hosemann, R., \& Balta-Calleja, F. (1973). Detection of "Memory" Effects in Polythethylene by Magnetic Susceptibility. Journal of Polymer Science: Polymer Physics Edition, 11, pp. 2273-2282

Porsani, J., Filho, W., Elis, V., Shimeles, F., Dourado, J., \& Moura, H (2004). The use of GPR and VES in delineating a contamination plume in a landfill site: a case study in SE Brazil. Journal of Applied Geophysics, 55, pp. 199-209.

Prezzi, C., Orgeira, M., Ostera, H., \& Vasquez, C. (2005). Ground magnetic survey of a municipal solid waste landfill: Pilot study in Argentina. Environmental Geology, 47, pp. 889-897.

Rakos, M., Murin, J., Kafka, D., Varga, Z., \& Olcak, D. (1984). NMR and Magnetic Susceptibility Study of Woods and Cellulose. Czechoslovakian Journal of Physics B, 34(4), pp. 322-340.

Savage, G., Golueke, C., \& von Stein, E. (1993). Landfill Mining. Past and present. Biocycle, 34(5), pp. 58-61.

Schenck, J. (1996). The role of magnetic susceptibility in magnetic resonance imaging: MRI magnetic compatibility of the first and second kinds. Medical Physics, 23(6), pp. 815-850.

Selwood, P., Pardo, J., \& Pace, A. (1950). Magnetic Anisotropy of Dimethyl Terephthalate and Polyethylene Terephthalate. Journal of the American Chemical Society, 72(3), pp. 1269-1276.

Soupios, P., Papadopoulos, I., Kouli, M., Georgaki, I., Vallianatos, F., \& Kokkinou, E. (2007). Investigation of waste disposal areas using electrical methods: a case study from Chania, Crete, Greece. Environmental Geology, 51(7), pp. 1249-1261.

Van De Vijver, E., \& Van Meirvenne, M. (2016). Delving into the potential of multi-receiver electromagnetic induction surveying for enhanced landfill exploration in view of ELFM. Proceedings of the Third International Academic Symposium on Enhanced Landfill Mining (ELFM III), (pp. 175-187). Lisboa.

Winterstetter, A., Laner, D., Rechberger, H., \& Fellner, J. (2015). Framework for the evaluation of anthropogenic resources: A landfill mining case study - Resource or reserve? Resources, Conservation and Recycling, 96, pp. 19-30.

Wolfsberger, T., Aldrian, A., Sarc, R., Hermann, R., Höllen, D., Budischowsky, A., Pomberger, R. (2015). Landfill mining: Resource potential of Austrian landfills - Evaluation and quality assessment of municipal solid waste by chemical analyses. Waste Management and Research, 33(11), pp. 962-974.

Yannah, M., Martens, K., van Camp, M., \& Walraevens, K. (2019). Geophysical exploration of an old dumpsite in the perspective of enhanced landfill mining in Kermt area, Belgium. Bulletin of Engineering Geology and the Environment, 78, pp. 55-67.

Zacharof, A. \&. (2004). Stochastic modelling of landfill processes incorporating waste heterogeneity and data uncertainty. Waste Management, 24, pp. 241-250.

Zanetti, M., \& Godio, A. (2006). Recovery of foundry sands and iron fractions from an industrial waste landfill. Resources, Conservation and Recycling, 48, pp. 396-411. 